\title{
Stable dye-sensitized solar cells based on organic chromophores and ionic liquid electrolyte
}

\author{
Daibin Kuang $^{\mathrm{a}, 1}$, Pascal Comte ${ }^{\mathrm{a}}$, Shaik M. Zakeeruddin ${ }^{\mathrm{a}, *}$, Daniel P. Hagberg ${ }^{\mathrm{b}}$, \\ Karl Martin Karlsson ${ }^{\mathrm{b}}$, Licheng Sun ${ }^{\mathrm{b}}$, Md.K. Nazeeruddin ${ }^{\mathrm{a}, *}$, Michael Grätzel ${ }^{\mathrm{a}, *}$ \\ ${ }^{a}$ Laboratory for Photonics and Interfaces, Institute of Chemical Sciences and Engineering, Ecole Polytechnique Federale de Lausanne, \\ 1015 Lausanne, Switzerland \\ ${ }^{\mathrm{b}}$ Organic Chemistry, Center of Molecular Devices, KTH Chemical Science and Engineering, SE-10044 Stockholm, Sweden
}

Available online 30 March 2011

Communicated by: Associate Editor Hari Upadhyaya

\begin{abstract}
A series of polyene-diphenylaniline based organic dyes (coded as D5, D7, D9 and D11) have been reported for the application in ionic liquid electrolyte based dye-sensitized solar cells. The effects of substitution of organic dyes on the photovoltaic performance have been investigated, which show addition of methoxy groups on the triphenylamine donor group increases short-circuit current, open-circuit voltage and photovoltaic performance. A power conversion efficiency of $6.5 \%$ under AM 1.5 sunlight at $100 \mathrm{~mW} / \mathrm{cm}^{2}$ has been obtained with D11 dye in combination with a binary ionic liquid electrolyte, which when subjected to accelerated testing under one sun light soaking at $60{ }^{\circ} \mathrm{C}$, the efficiency remained $90 \%$ of initial efficiency.
\end{abstract}

(C) 2011 Elsevier Ltd. All rights reserved.

Keywords: Organic dye; Ionic liquid; Nanocrystalline; Dye-sensitized solar cell; Impedance

\section{Introduction}

Renewable energy has recently attracted massive attention because of dwindling of traditional fossil energy, and high price. In this respect, solar energy is inexhaustible; about $3 \times 10^{24} \mathrm{~J}$ can be supplied to the Earth from the Sun per year, or about 10,000 times more than the global population currently consumes (Grätzel, 2001; O'Regan and Gratzel, 1991). Among the several technologies for converting solar energy into electricity mesoscopic dye-sensitized solar cells (DSCs) have attracted intense interest owing to cheap, and efficient (Grätzel, 2001, 2005; O'Regan and Gratzel, 1991, Wang et al., 2003). Since the first report of dye-sensitized solar cell in 1991, significant progress has

\footnotetext{
* Corresponding authors.

E-mail addresses: shaik.zakeer@epfl.ch (S.M. Zakeeruddin), mdkhaja.nazeeruddin@epfl.ch (Md.K. Nazeeruddin), michael.graetzel@ epfl.ch (M. Grätzel).

${ }^{1}$ Present address: School of Chemistry and Chemical Engineering, Sun Yat-Sen University, Guangzhou, Guangdong 510275, China.
}

been made through the development of photoanode materials, sensitizers, and electrolytes. The sensitizer is a crucial element in DSCs, exerting significant influence on the power conversion efficiency as well as the stability of the devices. A series of high-molar-extinction-coefficient ruthenium complexes containing $\pi$-conjugated ligand systems have been successfully introduced showing excellent photovoltaic performance and stability (Chen et al., 2006, 2007, 2008a,b, 2009; Karthikeyan et al., 2007; Kroeze et al., 2006; Gao et al., 2008a,b; Shi et al., 2008; Abbotto et al., 2008; Kuang et al., 2007a,b; Wang et al., 2005; Yu et al., 2010).

It is known that increase in the molar extinction coefficient and panchromatic response of the sensitizer can improve the solar cell performance. Metal-free organic dyes normally show higher molar extinction coefficients compared to the metal complexes. Further, they are environmentally friendly, easy to synthesize and cheap. Even though efficiencies are closer to $10 \%$ have been reached with metal free organic dyes, there is still a need to optimize their chemical and physical properties for further 
improvement of the device performance (Xu et al., 2009; Zang et al., 2009; Wang et al., 2008; Shi et al., 2008; Kim et al., 2008a,b; Choi et al., 2008a,b; Cid et al., 2007a,b; Yum et al., 2007; Ferrere et al., 1997; Ferrere and Gregg, 2002; Tian et al., 2000; Ito et al., 2006; Zhang et al., 2009, 2010; Mishra et al., 2009).

Ionic liquids (ILs) represent a new and attractive class of solvent free electrolytes, which are appealing due to their negligible vapor pressure under photovoltaic operating conditions as well as their high conductivity and thermal stability (Welton, 1999; Rogers et al., 2003; Wasserscheid and Welton, 2003; Dyson, 2002; Xue and Shreeve, 2005; Zhao et al., 2005). A number of ILs have already been examined for DSCs (Kuang et al., 2006; Kubo et al., 2002; Kawano et al., 2004; Matsumoto et al., 2001; Wang et al., 2005; Mazille et al., 2006; Fei et al., 2006; Zakeeruddin et al., 2009; Kuang et al., 2007; Bai et al., 2008; Wang et al., 2004; Zakeeruddin and Grätzel, 2009). Here we report detailed photovoltaic performance investigations based on a series of polyene-diphenylaniline based dyes and ionic liquid electrolyte resulting a power conversion efficiency of $6.5 \%$ under AM 1.5 sunlight at $100 \mathrm{~mW} / \mathrm{cm}^{2}$, which shows excellent stability behavior after long-term accelerated tests under one sun light illumination at $60^{\circ} \mathrm{C}$. Electrochemical impedance and photovoltage transient studies reveal the pivotal influence exerted by the chemical structure of the polyene-diphenylaniline based organic dyes on the photovoltaic performance of the device.

\section{Results and discussion}

Fig. 1 shows molecular structures of the four new dyes, which were synthesized using previously reported synthetic routes (Hagberg et al., 2008, 2006; Qin et al., 2007). The structure of D5 sensitizer was modified with the addition diphenylaniline and methoxy groups which named as D7, D9, D11 dyes. The molar extinction coefficients of the D5, D7, D9 and D11 dyes are $33,000 \mathrm{M}^{-1} \mathrm{~cm}^{-1}(441 \mathrm{~nm})$, $31,000 \mathrm{M}^{-1} \mathrm{~cm}^{-1} \quad(441 \mathrm{~nm}), \quad 33,000 \mathrm{M}^{-1} \mathrm{~cm}^{-1}(464 \mathrm{~nm})$ and $38,000 \mathrm{M}^{-1} \mathrm{~cm}^{-1}(458 \mathrm{~nm})$, respectively.

Fig. 2 presents the current-voltage characterizations of the DSCs based on the four organic dyes using a binary ionic liquid electrolyte. It shows that the short-circuit current density $\left(J_{\mathrm{sc}}\right)$ of the DSCs is in the order of D9 $>$ D11 $>$ D5 $>$ D7 and the open-circuit voltage $\left(V_{\mathrm{oc}}\right)$ is D11 $>$ D9, D7 $>$ D5. The $J_{\mathrm{sc}}, V_{\mathrm{oc}}, \mathrm{FF}$ and efficiency of DSCs based on D11 dye are $12.4 \mathrm{~mA} \mathrm{~cm}^{-2}, 714 \mathrm{mV}$, $0.73 \%$, and $6.5 \%$, respectively, which is the highest photovoltaic performance in the series. The detailed photovoltaic parameters of the DSCs based on different sensitizers are presented in Table. 1. The addition of second diphenylaniline donor group results in lowering the short-circuit current, which can be seen by comparing the analogous dyes D5 and D7, and D9 and D11. From the photovoltaic parameters of D5 vs. D9, and D7. vs. D11, shows that the addition of methoxy group on the dye molecular structure increases the current and voltage. The incident photon to current efficiency (IPCE) curves of the DSCs based on these dyes are shown in Fig. 2b. To understand the influence of structural changes of dyes on the photovoltaic performance we used the same $\mathrm{TiO}_{2}$ film and electrolyte with different dyes. Apparently, addition of the methoxy group on the molecular structure of the dye (D9 and D11) shift the absorption maxima to longer wavelength resulting higher short-circuit current density when compared to analogous dyes without methoxy groups D5 and D7.

Further analysis was performed to clarify this intriguing behavior. The dark current curves in Fig. 2a indicate that D11 has a more negative onset potential for the reduction of $I_{3}^{-}$than the D5, D7 or D9 dyes. One possible explanation
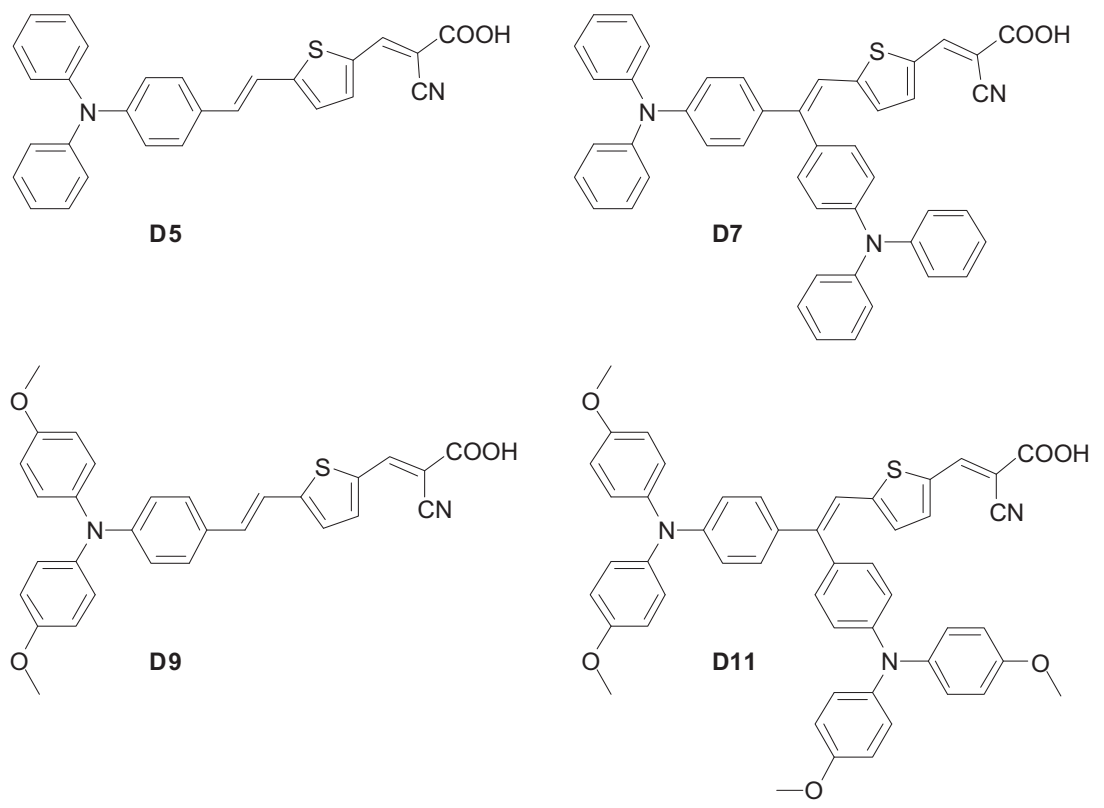

Fig. 1. Molecular structures of D5, D7, D9 and D11 sensitizers. 

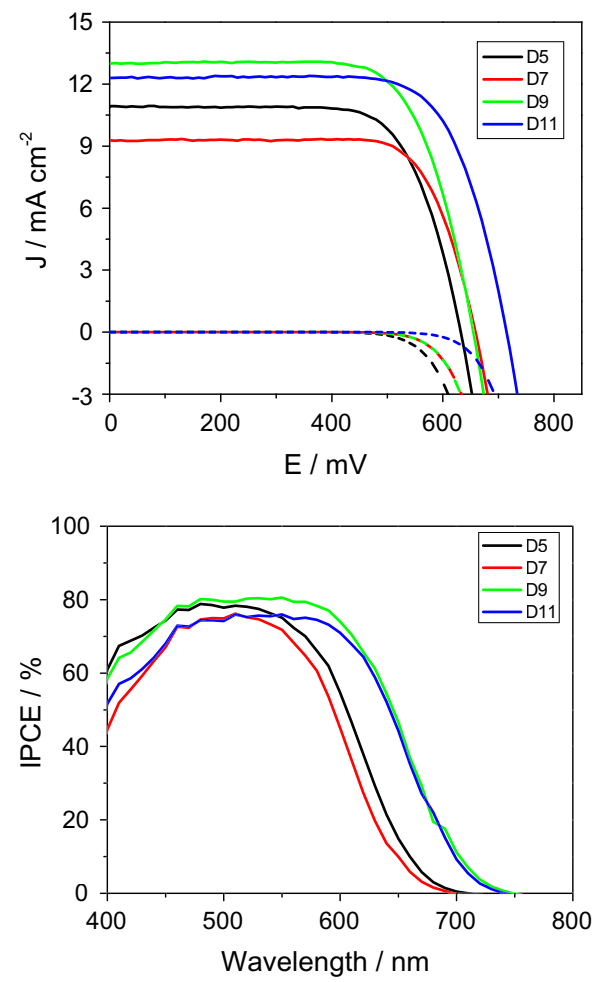

Fig. 2. (a) Current density-voltage characteristics and (b) photocurrent action spectra of the ionic liquid electrolyte based DSCs for devices with D5, D7, D9, and D11 sensitizers, respectively.

Table 1

Detailed photovoltaic parameters of the IL-based DSCs using D5, D7, D9 or D11 sensitizers under AM 1.5 one sun $\left(100 \mathrm{~mW} / \mathrm{cm}^{2}\right)$ light intensities. ${ }^{a}$

\begin{tabular}{lllll}
\hline & $J_{\mathrm{SC}}\left(\mathrm{mA} / \mathrm{cm}^{2}\right)$ & $V_{\mathrm{OC}}(\mathrm{mV})$ & $\mathrm{FF}$ & $\eta(\%)$ \\
\hline D5 & 10.9 & 632 & 0.72 & 4.9 \\
D7 & 9.3 & 658 & 0.75 & 4.6 \\
D9 & 13.1 & 654 & 0.71 & 6.1 \\
D11 & 12.4 & 714 & 0.73 & 6.5 \\
\hline
\end{tabular}

${ }^{\mathrm{a}}$ The spectral distribution of the xenon lamp simulates air mass 1.5 solar light. 1.0 sun was mismatch corrected to correspond AM 1.5 global sunlight $\left(100 \mathrm{~mW} / \mathrm{cm}^{2}\right)$. The cell active areas were $0.158 \mathrm{~cm}^{-2}$.

for this observation is that the rate constant of reaction of free $\mathrm{TiO}_{2}$ conduction band electrons with triiodide ions at a given forward bias potential is decreased by substituting with methoxy group and/or triphenylamine group. Alternatively the lower dark current could also be rationalized in terms of a negative shift in the conduction band edge of the $\mathrm{TiO}_{2}$ caused by the adsorption of the D11 dye.

In the impedance spectra of ionic liquid electrolyte based DSCs, normally there are three semi-circle in Nyquist plots or three frequency peak in Bode phase plots, which corresponding to triiodide diffusion in the electrolyte, electron recombination at the $\mathrm{TiO}_{2} /$ electrolyte interface and electron transportation in the $\mathrm{TiO}_{2}$ nanoparticles, charge transfer at the counter electrode. As shown in Fig. 3, in the Nyquist plots of the DSCs measured under dark at $-0.65 \mathrm{~V}$ applied bias clearly shows that the middle semi-circle increase in the order of D5 $>$ D7 $\sim$ D9 $>$ D11. The increased recombination resistance is expected to enhance the electron lifetime for D11 compared to other dyes. The middle semicircle was fitted by using certain physical model, which shows the electron lifetime of the DSCs based on D5, D7, D9 and D11, is $12.0 \mathrm{~ms}, 15.2 \mathrm{~ms}, 13.5 \mathrm{~ms}$ and $59.8 \mathrm{~ms}$, respectively. The observed longer electron lifetime for D11 was reflected in obtaining the higher open circuit potential.

Photocurrent and photovoltage transient studies were performed to further scrutinize the different photovoltaic behavior of the four polyene-diphenylaniline dyes. Fig. 4 shows electron lifetimes of DSCs based on D5, D7, D9 and D11 dyes under corresponding $V_{\text {oc }}$ values resulting from various bias light intensities. The measured electron lifetimes of DSCs based on D11 dye are seen to be longer than those utilizing D5, D7 and D9 dyes under various open circuit potentials. This observation can be ascribed to the effective suppression of electron recombination, in agreement with the EIS results described above. The electron lifetime values of DSCs based on D5, D7, D9 and D11 measured at a potential of $-0.65 \mathrm{~V}$ are $3.9 \mathrm{~ms}$, $8.1 \mathrm{~ms}, 5.6 \mathrm{~ms}$ and $22.9 \mathrm{~ms}$, respectively, are smaller than those obtained from the EIS data. These differences can be rationalized in terms of different local $I_{3}^{-}$concentrations present in the pores of the nanocrystalline $\mathrm{TiO}_{2}$ film and different conduction band electron concentration. Photovoltage transient decay studies of the DSC performed under illumination refer to a higher $I_{3}^{-}$concentration than that found in the EIS experiments that were measured in the dark.

The exploration of stable DSCs based on organic dye is attractive because of its low cost and reasonable high efficiency. Though some DSCs systems based on ruthenium complex sensitizer have shown excellent photovoltaic performance and stability during the long-term accelerated tests, the organic dye-sensitized solar cells still remains a challenge for the point of stability. Here DSCs based on present four organic dyes were further investigated for the long-term accelerated test under full sun light soaking at $60^{\circ} \mathrm{C}$. Fig. 5 shows the normalized efficiency versus aging time for the cells sensitized with D5, D7, D9 and D11sensitizers, which reveal there was $30 \%, 25 \%, 18 \%$, $9.4 \%$ drop compared to the corresponding initial efficiency

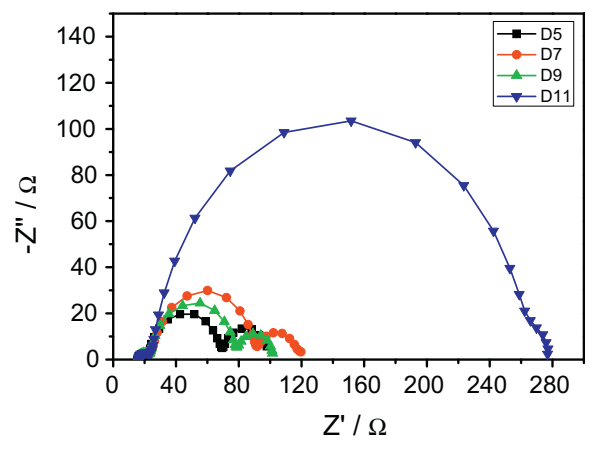

Fig. 3. Impedance spectra (Nyquist plots) of DSC devices based on D5, D7, D9, and D11 dyes measured at $-0.65 \mathrm{~V}$ bias in the dark. 


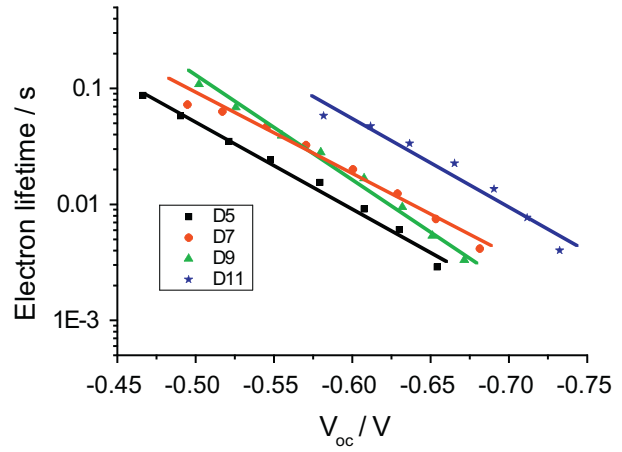

Fig. 4. Electron lifetimes of the devices based on binary IL electrolyte and D5, D7, D9 or D11 sensitizers at open-circuit voltage under various light bias.

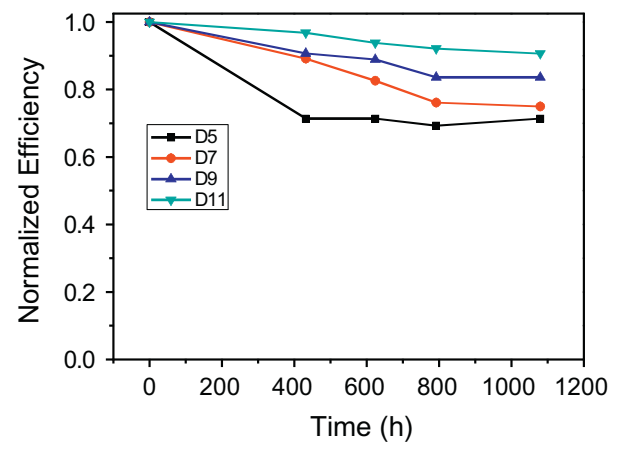

Fig. 5. Normalized photovoltaic efficiency varies for the DSCs based on four organic dyes with the aging time under full sun illumination at $60^{\circ} \mathrm{C}$.

after $1000 \mathrm{~h}$ accelerated test, respectively. The main decay of the photovoltaic performance arises from the $V_{\mathrm{oc}}$ and FF drop. The comparison of the data of D5 and D7 shows that the extra triphenylamine group can contribute to the stability of DSCs. Further, improvement can be obtained by using a methoxy groups (see D5 and D9 data). Finally, the organic dye (D11) with more triphenylamine and methoxy groups show excellent $(90 \%)$ stability implying the effect of the molecular structure on the stability of DSCs. This may show new trend of development of organic dyes and will stimulate research and practical application prospects of organic dye based solar cells.

Fig. 6 further presents the detailed photovoltaic performance parameters varied with aging time, which based on D11 dye and present binary ionic liquid electrolyte during the light soaking accelerated test. After $1000 \mathrm{~h}$ accelerated test, the current is slightly higher than the initial value, however there is a $\sim 50 \mathrm{mV}$ decay in $V_{\text {oc }}$ and $3 \%$ decrease in $\mathrm{FF}$, finally the efficiency remains $90.5 \%$ of initial value. Here the current does not decrease even after $1000 \mathrm{~h}$ light soaking accelerated test showing the D11 sensitizer's anchoring strength onto the $\mathrm{TiO}_{2}$ surface. Fig. 7 present the Nyquist plots of the DSCs based on D11 dye for the fresh cell and after $1000 \mathrm{~h}$ light soaking accelerated test. From the Nyquist plots we can see the recombination resistance decrease during the aging, which results in the electron lifetime decrease from $59.8 \mathrm{~ms}$ to $19.2 \mathrm{~ms}$. This

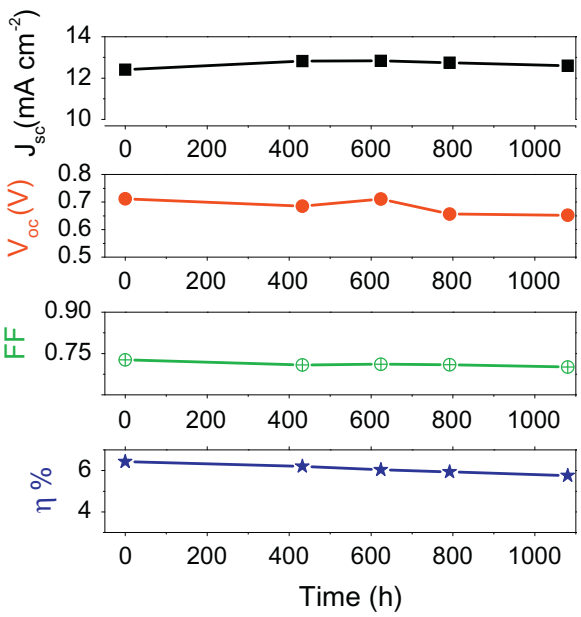

Fig. 6. Detailed photovoltaic parameter $\left(J_{\mathrm{SC}}, V_{\mathrm{OC}}, \mathrm{FF}\right.$ and $\left.\eta\right)$ variations with aging time for the device based on D11 and ionic liquid electrolyte during successive aging under full sun illumination at $60^{\circ} \mathrm{C}$.

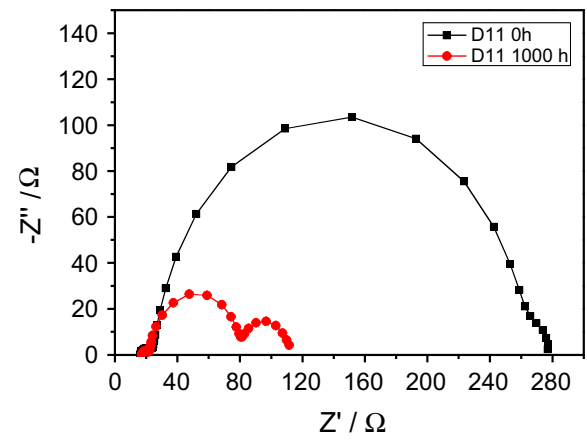

Fig. 7. Impedance spectra (Nyquist plots) of DSC devices based on D11 and ionic liquid electrolyte for fresh cell and aged cell after $1000 \mathrm{~h}$ acceleration testing under full sun illumination at $60{ }^{\circ} \mathrm{C}$, measured at $-0.65 \mathrm{~V}$ applied bias in dark.

implies the photovoltage decay for the aged cell which is reasonably in accordance with the observed photovoltage performance variation.

In conclusion, the present study of polyene-diphenylaniline based organic dyes (D5, D7, D9, D11) reveals the influence of molecular engineering of sensitizers on the photovoltaic performance and the stability of devices. Impedance and photovoltage transient studies show that the electron lifetime of the DSCs is in the order D5 $<$ D7 $\sim$ D9 $<$ D11. The stability behaviors of the DSCs exhibit significant difference for the four organic dyes. Finally, a power conversion efficiency of $6.5 \%$ was achieved with D11 dye in combination of ionic liquid electrolyte that shows $90 \%$ of initial efficiency after $1000 \mathrm{~h}$ accelerated test under full sun light soaking at 60 degrees.

\section{Experimental}

\subsection{Reagents}

The four polyene-diphenylaniline based organic dyes were synthesized according to previous procedure (Hagberg et al., 2008, 2006; Qin et al., 2007) and 1-butyl- 
1H-benzimidazole (NBB) were synthesized as reported earlier (Abbotto et al., 2008). The ILs 1-propyl-3-methylimidazolium iodide (PMII) was synthesized according to the literature methods and the purity was confirmed by ${ }^{1} \mathrm{H}$ NMR analysis. Guanidinium thiocyanate (GuNCS) and 1-ethyl-3-methyl-imidazolium tetracyanoborate $\left(\operatorname{EMIB}(\mathrm{CN})_{4}\right)$ ionic liquid were purchased from SigmaAldrich and Merck, respectively.

\subsection{Electrochemical impedance spectroscopy}

Impedance spectra of DSCs were measured in the dark at $-0.7 \mathrm{~V}$ forward bias using a potentiostat (EG\&G, M273) equipped with a frequency response analyzer (EG\&G, M1025). The spectra were scanned in a frequency range of $0.005 \mathrm{~Hz} \sim 100 \mathrm{kHz}$ at room temperature with modulation amplitude set at $10 \mathrm{mV}$. The obtained impedance spectra were fitted with Z-View software (v2.8b, Scribner Associates Inc.) to the appropriated equivalent circuits (Bisquert, 2002, 2003; van de Lagemaat et al., 2000; Bisquert et al., 2004; Wang et al., 2005; Kern et al., 2002; Fabregat-Santiago et al., 2007).

\subsection{Photovoltage transient decay}

Transient photovoltage measurements employed an $200 \mathrm{~ms}$ exciting pulse generated by a ring of red light emitting diodes (LEDs, Lumiled) controlled by a fast solid-state switch. The pulse was incident on the $\mathrm{TiO}_{2}$ side of the device and its intensity was controlled to keep the modulation of the voltage below $5 \mathrm{mV}$ so that the relaxation kinetics was of first order. White bias light impinging the cell from the same direction was also supplied by LEDs. Transients were measured at different white light intensities ranging from $150 \%$ to $0.1 \%$ of $\mathrm{AM} 1.5$ solar light $\left(1000 \mathrm{~W} / \mathrm{m}^{2}\right)$ and adjusted via tuning of the voltage applied to the bias diodes.

\subsection{Preparation of mesoscopic $\mathrm{TiO}_{2}$ films and fabrication of DSCS}

The mesoscopic $\mathrm{TiO}_{2}$ films used as photoanodes consisted of double layers of $\mathrm{TiO}_{2}(6 \mu \mathrm{m}$ thick transparent layer of $20 \mathrm{~nm} \mathrm{TiO}{ }_{2}$ anatase nanoparticles and $4 \mu \mathrm{m}$ thick scattering layer of $400 \mathrm{~nm}$ anatase $\mathrm{TiO}_{2}$ particles). The detailed method of $\mathrm{TiO}_{2}$ film preparation, device fabrication and the photocurrent-voltage measurements was reported in our earlier publications. (Wang et al., 2003) The double layer films were heated to $520^{\circ} \mathrm{C}$ and sintered for $30 \mathrm{~min}$, then cooled to $\sim 80^{\circ} \mathrm{C}$ and immersed into the dye solution containing $300 \mathrm{M}$ of organic dye in acetonitrile and tert-butyl alcohol (volume ratio: 1:1) at room temperature for $16 \mathrm{~h}$. Dye coated double layer films were assembled and sealed with $25 \mu \mathrm{m}$ thick Surlyn hot-melt rings (DuPont) to the counter electrodes. The latter employed FTO glass with small amount of Pt catalyst deposited from $0.005 \mathrm{M}$ hexachloroplatinic acid solution in isopropanol and subsequent heating at $400{ }^{\circ} \mathrm{C}$ for $15 \mathrm{~min}$. The electrolyte was injected into the inter electrode space from the counter electrode side through a predrilled hole that was subsequently sealed with a Bynel sheet and a thin glass slide cover by heating. The binary ionic liquid electrolyte consisted of $0.2 \mathrm{M}$ iodine, $0.5 \mathrm{M}$ $\mathrm{NBB}$, and $0.1 \mathrm{M}$ GuNCS in a mixture of PMII and $\operatorname{EMIB}(\mathrm{CN})_{4}$ their volume ratio being 65:35. The assembly and photovoltaic characterization of the devices were described in detail elsewhere (Kuang et al., 2006).

\subsection{Photocurrent-voltage measurements}

The light source for the photocurrent-voltage (I-V) measurement was a $450 \mathrm{~W}$ xenon lamp (Oriel, USA), simulating AM 1.5 solar light. The incident light intensity was calibrated with a standard Si solar cell. The spectral output of the lamp was matched precisely to the standard global AM 1.5 solar spectrum in the region of $350-750 \mathrm{~nm}$ (mismatch $<2 \%$ ) by the aid of a Schott K113 Tempax sunlight filter (Präzisions Glas \& Optik GmbH, Germany). Various irradiance intensities (from 0.01 to 1.0 sun) were provided with neutral wire mesh attenuators. The current-voltage curves were obtained by measuring the photocurrent of the cells using a Keithley model 2400 digital source meter (Keithley, USA) under an applied external potential scan. The current and voltage transient measurements employed the same system. The measurement of incident photon-tocurrent conversion efficiency (IPCE) was recorded by a data collecting system as a function of excitation wavelength. The incident light from a $300 \mathrm{~W}$ xenon lamp (ILC Technology, USA) was focused through a Gemini-180 double monochromator (Jobin Yvon Ltd., UK) onto the cell under test. No white light bias was applied and the $\mathrm{dc}$ photocurrents were in a domain where their response to light intensity was linear.

\subsection{Stability test}

Hermetically sealed cells were used to check the longterm stability under visible light soaking at $60{ }^{\circ} \mathrm{C}$. The light soaking experiments employed a polymer film of $50 \mu \mathrm{m}$ thickness (Preservation Equipment Ltd., UK), eliminating UV light. Cells were exposed at open circuit to a Suntest CPS lamp (ATLAS GmbH, $100 \mathrm{~mW} / \mathrm{cm}^{2}, 60^{\circ} \mathrm{C}$ ) over a period of $1000 \mathrm{~h}$. The cells were taken out at regular intervals to record the photocurrent-voltage curve.

\section{Acknowledgment}

We acknowledge the financial support of this work by the Swiss Swiss National Science Foundation, Swedish Research Council, Swedish Energy Agency and the Knut and Alice Wallenberg foundation for financial support. MKN thanks the World Class University (WCU) program funded by the Ministry of Education, Science and Technology (Grant No. R31-2009-000-10035-0). 


\section{References}

Abbotto, A., Barolo, C., Bellotto, L., De Angelis, F., Grätzel, M., Manfredi, N., Marinzi, C., Fantacci, S., Yum, J., Nazeeruddin, M., 2008. Chem. Commun., 5318.

Bai, Y., Cao, Y.M., Zhang, J., Wang, M., Li, R.Z., Wang, P., Zakeeruddin, S.M., Graetzel, M., 2008. Nat. Mater. 7 (8), 626.

Bisquert, J., 2002. J. Phys. Chem. B. 106, 325.

Bisquert, J., 2003. Phys. Chem. Chem. Phys. 5, 5360.

Bisquert, J., Zaban, A., Greenshtein, M., Mora-Sero, I., 2004. J. Am. Chem. Soc. 126, 13550.

Chen, C., Wu, S., Wu, C., Chen, J., Ho, K., 2006. Angew. Chem. Int. Ed. $45,5822$.

Chen, C., Wu, S., Li, J., Wu, C., Chen, J., Ho, K., 2007. Adv. Mater. 9, 3888.

Chen, C., Chen, J., Wu, S., Li, J., Wu, C., Ho, K., 2008a. Angew. Chem. 120,7452 .

Chen, C., Chen, J., Wu, S., Li, J., Wu, C., Ho, K., 2008b. Angew. Chem. Int. Ed. 47, 7342.

Chen, Chia-Yuan, Wang, Mingkui, Li, Jheng-Ying, Pootrakulchote, Nuttapol, Alibabaei, Leila, Ngoc-le, Cevey-ha, Decoppet, Jean-David, Tsai, Jia-Hung, Grätzel, Carole, Wu, Chun-Guey, Zakeeruddin, Shaik M., Grätzel, Michael, 2009. ACS Nano. 3 (10), 3103.

Choi, H., Baik, C., Kang, S.O., Ko, J., Kang, M.-S., Nazeeruddin, Md.K., Grätzel, M., 2008a. Angew. Chem. 120, 333.

Choi, H., Baik, C., Kang, S.O., Ko, J., Kang, M.-S., Nazeeruddin, Md.K., Grätzel, M., 2008b. Angew. Chem. Int. Ed. 47, 327.

Cid, J.-J., Yum, J.-H., Jang, S.-R., Nazeeruddin, M.K., Mart_nezFerrero, E., Palomares, E., Ko, J., Gr_tzel, M., Torres, T., 2007a. Angew. Chem. 119, 8510.

Cid, J.-J., Yum, J.-H., Jang, S.-R., Nazeeruddin, M.K., Mart nezFerrero, E., Palomares, E., Ko, J., Gr_tzel, M., Torres, T., 2007b. Angew. Chem. Int. Ed. 46, 8358.

Dyson, P., 2002. Transit. Metal Chem. 27, 353.

Fabregat-Santiago, F., Bisquert, J., Palomares, E., Otero, L., Kuang, D., Zakeeruddin, S.M., Grätzel, M., 2007. J. Phys. Chem. C 111 (17), 6551.

Fei, Z.F., Kuang, D.B., Zhao, D.B., Klein, C., Ang, W.H., Zakeeruddin, S.M., Gratzel, M., Dyson, P., 2006. J. Inorg. Chem. 45, 10407.

Ferrere, S., Gregg, B.A., 2002. New J. Chem. 26, 1155.

Ferrere, S., Zaban, A., Gregg, B.A., 1997. J. Phys. Chem. B 101, 4490.

Gao, F., Wang, Y., Zhang, J., Shi, D., Wang, M., Humphry-Baker, R., Wang, P., Zakeeruddin, S., Grätzel, M., 2008a. Chem. Commun., 2635.

Gao, F., Wang, Y., Shi, D., Zhang, J., Wang, M., Jing, X., HumphryBaker, R., Wang, P., Zakeeruddin, S., Grätzel, M., 2008b. J. Am. Chem. Soc. 130, 10720.

Grätzel, M., 2001. Nature 414, 338.

Gratzel, M., 2005. Inorg. Chem. 44, 6841.

Hagberg, D.P., Edvinsson, T., Marinado, T., Boschloo, G., Hagfeldt, A., Sun, L.C., 2006. Chem. Commun., 2245.

Hagberg, D.P., Yum, J.H., Lee, H., De Angelis, F., Marinado, T., Karlsson, K.M., Humphry-Baker, R., Sun, L.C., Hagfeldt, A., Gratzel, M., Nazeeruddin, M.K., 2008. J. Am. Chem. Soc. 130, 6259.

Ito, S., Zakeeruddin, S.M., Humphry-Baker, R., Liska, P., Charvet, R., Comte, P., Nazeeruddin, M.K., Pechy, P., Takata, M., Miura, H., Uchida, S., Grätzel, M., 2006. Adv. Mater. 18, 1202.

Karthikeyan, C., Wietasch, H., Thelakkat, M., 2007. Adv. Mater. 19, 1091.

Kawano, R., Matsui, H., Matsuyama, C., Sato, A., Susan, M.A.B.H., Tanabe, N., Watanabe, M., 2004. J. Photochem. Photobiol. A 164, 87.

Kern, R., Sastrawan, R., Ferber, J., Stangl, R., Luther, J., 2002. Electrochim. Acta 47, 4213.

Kim, C., Choi, H., Kim, S., Baik, C., Song, K., Kang, M.-S., Kang, S.O., Ko, J., 2008a. J. Org. Chem. 73, 7072.

Kim, J.J., Choi, H., Lee, J.-W., Kang, M.-S., Song, K., Kang, S.O., Ko, J., 2008b. J. Mater. Chem. 18, 5223.

Kroeze, J., Hirata, N., Koops, S., Nazeeruddin, M., Schmidt-Mende, L., Grätzel, M., Durrant, J., 2006. J. Am. Chem. Soc. 128, 16376.
Kuang, D., Wang, P., Ito, S., Zakeeruddin, S.M., Gratzel, M., 2006. J. Am. Chem. Soc. 128, 7732.

Kuang, D., Ito, S., Wenger, B., Klein, C., Moser, J.E., Humphry-Baker, R., Zakeeruddin, S.M., Gratzel, M., 2006. J. Am. Chem. Soc. 128, 4146.

Kuang, D., Klein, C., Ito, S., Moser, J.E., Humphry-Baker, R., Evans, N., Duriaux, F., Gratzel, C., Zakeeruddin, S.M., Gratzel, M., 2007a. Adv. Mater. 19, 1133.

Kuang, D., Klein, C., Ito, S., Moser, J-E., Humphry-Baker, R., Zakeeruddin, S.M., Grätzel, M., 2007b. Adv. Funct. Mater. 17, 154.

Kubo, W., Kitamura, T., Hanabusa, K., Wada, Y., Yanagida, S., 2002. Chem. Commun., 374.

Matsumoto, H., Matsuda, T., Tsuda, T., Hagiwara, R., Ito, Y., Miyazaki, Y., 2001. Chem. Lett., 26.

Mazille, F., Fei, Z.F., Kuang, D.B., Zhao, D., Zakeeruddin, S.M., Gratzel, M., Dyson, P., 2006. Inorg. Chem. 45 (1), 585.

Mishra, A., Fischer, M.K.R., Ba€uerle, P., 2009. Angew. Chem. Int. Ed. 48, 2474, and references cited therein.

O’Regan, B., Gratzel, M., 1991. Nature 353, 737.

Qin, P., Yang, X.C., Chen, R.K., Sun, L.C., Marinado, T., Edvinsson, T., Boschloo, G., Hagfeldt, A., 2007. J. Phys. Chem. C 111, 1853.

Rogers, R.D., Seddon, K.R., Volkov, S. (Eds.), 2003. Green Industrial Applications of Ionic Liquids. Kulwer Academic Press.

Shi, D., Pootrakulchote, N., Li, R., Guo, J., Wang, Y., Zakeeruddin, S., Grätzel, M., Wang, P., 2008. J. Phys. Chem. C 112, 17046.

Shi, D., Cao, Y., Pootrakulchote, N., Yi, Z., Xu, M., Zakeeruddin, S.M., Grätzel, M., Wang, P., 2008. J. Phys. Chem. C 112 (44), 17478.

Tian, H., Liu, P.-H., Zhu, W., Gao, E., Wu, D.-J., Cai, S.J., 2000. Mater. Chem. 12, 2708.

van de Lagemaat, J., Park, N.G., Frank, A.J., 2000. J. Phys. Chem. B 104, 2044.

Wang, P., Zakeeruddin, S.M., Moser, J.E., Nazeeruddin, M.K., Sekiguchi, T., Gratzel, M., 2003. Nat. Mater. 2, 402.

Wang, P., Zakeeruddin, S.M., Comte, P., Charvet, R., Humphry-Baker, R., Grätzel, M., 2003. J. Phys. Chem. B 107, 14336.

Wang, P., Zakeeruddin, S.M., Graetzel, M., Kantlehner, W., Mezger, J., Stoyanov, E.V., Scherr, O., 2004. Appl. Phys. A: Mater. Sci. Process. 79 (1), 73-77.

Wang, P., Klein, C., Humphry-Baker, R., Zakeeruddin, S.M., Grätzel, M., 2005. Appl. Phys. Lett. 86, 123508.

Wang, P., Wenger, B., Humphry-Baker, R., Moser, J.E., Teuscher, J., Kantlehner, W., Mezger, J., Stoyanov, E.V., Zakeeruddin, S.M., Gratzel, M., 2005. J. Am. Chem. Soc. 127, 6850.

Wang, Q., Moser, J.E., Gratzel, M., 2005. J. Phys. Chem. B 109, 14945.

Wang, Mingkui, Xu, Mingfei, Shi, Dong, Li, Renzhi, Gao, Feifei, Zhang, Guangliang, Yi, Zhihui, Humphry-Baker, Robin, Wang, Peng, Zakeeruddin, Shaik M., Gratzel, Michael, 2008. Adv. Mater. 20 (23), 4460.

Wasserscheid, P., Welton, T., 2003. Ionic Liquids in Synthesis. Wiley$\mathrm{VCH}$, Weinheim, Germany.

Welton, T., 1999. Chem Rev. 99, 2071

Xu, Mingfei, Wenger, Sophie, Bala, Hari, Shi, Dong, Li, Renzhi, Zhou, Yanzhou, Zakeeruddin, Shaik M., Grätzel, Michael, Wang, Peng, 2009. J. Phys. Chem. 113 (7), 2966-2973.

Xue, H., Shreeve, J.M., 2005. Eur. J. Inorg. Chem., 2573.

Yu, Qingjiang, Zhou, Difei, Shi, Yushuai, Si, Xiaoying, Wang, Yinghui, Wang, Peng, 2010. Energy Environ. Sci. 3, 1722.

Yum, H., Jang, S.-R., Walter, P., Geiger, T., Nüesch, F., Kim, S., Ko, J., Grätzel, M., Nazeeruddin, M.K., 2007. Chem. Commun., 4680.

Zakeeruddin, S.M., Grätzel, M., 2009. Adv. Funct. Mater. 19, 2187.

Zang, G., Bai, Y., Li, R., Shi, D., Wenger, S., Zakeeruddin, S.M., Graetzel, M., Wang, P., 2009. Energy Environ. Sci. 2 (1), 92.

Zeng, Wangdong, Cao, Yiming, Bai, Yu., Wang, Yinghui, Shi, Yushuai, Zhang, Min, Wang, Fangfang, Pan, Chunyue, Wang, Peng., 2010. Chem. Mater. 22, 1915.

Zhang, G., Bala, H., Cheng, Y., Shi, D., Lv, X., Yu, Q., Wang, P., 2009. Chem. Commun., 2198.

Zhao, F.F., Geldbach, T.J., Zhao, D.B., Dyson, P.J., 2005. Chem. - Eur. J. 12, 2122. 